\title{
Orange-Brown Pigment Production from an Endophytic Fungus Aspergillus Sp. N11 and its Potential Pharmaceutical Applications
}

\author{
Madeha Ashfaq \\ Quaid-i-Azam University \\ Qurban Ali \\ Quaid-i-Azam University \\ Abdul Haleem \\ Quaid-i-Azam University \\ Aman Ullah \\ Quaid-i-Azam University \\ Aiman Umar \\ Quaid-i-Azam University \\ Irfan Ullah \\ Quaid-i-Azam University \\ SAFIA AHMED ( $\nabla$ safiamrl@yahoo.com ) \\ QUAID-I-AZAM UNIVERSITY https://orcid.org/0000-0001-9773-6433
}

\section{Research Article}

Keywords: Antimicrobial, Antioxidant, Astaxanthin, Carotenoids, Endophytes, Fungal pigments

Posted Date: January 3rd, 2022

DOI: https://doi.org/10.21203/rs.3.rs-1126132/v1

License: (9) This work is licensed under a Creative Commons Attribution 4.0 International License. Read Full License 


\section{Abstract}

Endophytic fungi are the main source of natural compounds including pigments having various industrial applications. Present study describes the production of extracellular orange-brown pigment from an endophytic fungal isolate Aspergillus sp. N11from Teucrium stocksianum. The optimum conditions for pigment production from this isolate was investigated and results showed that highest yield was observed in Potato dextrose broth, at $\mathrm{pH} 5$ and $30^{\circ} \mathrm{C}$ under shaking condition at $150 \mathrm{rpm}$ for 7-10 days. The pigment was extracted in ethyl acetate and purified using column chromatography. Three different pigments were purified (yellow, light brown and orange-brown) and characterized based on Thin layer chromatography and Fourier transform infrared spectroscopy. The antimicrobial activity of purified fragments showed maximum zone of inhibition of $40 \mathrm{~mm}$ against $S$. aureus while for $P$. aeruginosa maximum zone of $50 \mathrm{~mm}$ and maximum antifungal activity of $20 \mathrm{~mm}$ against $C$. albicans. The antioxidant potential of purified pigment obtained from Aspergillus sp. N11 indicates that maximum scavenging activity of $67 \%$. The results showed that purified pigments are astaxanthins belonging to oxygen containing carotenoids. The purified astaxanthins showed antibacterial, antifungal and antioxidant activities indicating its potential to be utilized in pharmaceutical and food industries.

\section{Introduction}

Pigments are being used by mankind from primeval times for various purposes (Bisht et al. 2020). Dyeing and painting was practiced during bronze era of Europe. Use of natural dyes were first discovered from China and Indus Valley 2500 BC. These findings were proved to be right when colored fabrics and madder dye traces were found from remains of Harappa and Mohenjodaro. In Egypt mummies were found covered in stained cloths (Siva 2017). These coloring agents were obtained conventionally from plants such as pepper, red beets, grapes, berries, saffron and turmeric (Aberoumand 2011). With the advancement of science synthetic pigments were utilized because of their stability and low cost. However, their use is now limited because of their carcinogenicity, toxicity, hyper-allergic reactions and genotoxicity (Chandi and Gill 2011). Synthetic dyes used as food additives cause hyperactive behaviors in children (McCann et al. 2007). Three dyes (Red 40, Yellow 5 and Yellow 6) contains carcinogens such as benzidine, cause hypersensitivity reactions and are also genotoxic (Kobylewski and Jacobson 2012). Moreover, these synthetic pigments are the leading cause of contamination of aquatic environments. Most of them are non-biodegradable or produce carcinogen upon transformation into by products (Khorasanizadeh et al. 2019; Tkaczyk et al. 2020). Natural pigments derived from plants and microorganisms are most appropriate alternative of these hazardous synthetic pigments (Akilandeswari and Pradeep 2016). Microbial pigments are preferred over plant pigments because of their fast growth cycle using cheaper culture mediums, their availability is not dependent on weather conditions (Venil 2009), easy processing and high stability and solubility (Rao et al. 2017). To increase the growth and yield of pigments different biotechnological approaches are applied in industries. Parameters such as growth medium, temperature, $\mathrm{pH}$, carbon and nitrogen source, incubation time and aeration effect secondary metabolite production and must be regulated (Visalakchi and Muthumary 2010). 
Endophytic micro-organisms such as bacteria, fungi, algae are the main source of various natural products having bioactive potential. These secondary metabolites include pigments (Julistiono et al. 2021), antioxidants (da Silva et al. 2020), anticancer, anti-inflammatory and antimicrobial compounds (Menezes et al. 2020; Mishra et al. 2021; Tang et al. 2020). Thousands of endophytic isolates have been identified having potential properties and are being used in different industries. Filamentous fungi are the main pigment producers (Suwannarach et al. 2019a). Fungi can produce an extraordinary range of pigments having different applications. Carotenoids are the largest group of pigments produced by a range of fungal species such as Aspergillus, Aschersonia, Cercospora, Penicillium, Rhodosporidium, Sclerotium, Sclerotinia, Sporidiobolus, Ustilago, Blakeslea, Mucor, Phycomyces (Avalos and Limón 2015; Meruvu and Dos Santos 2021). Many other pigments such as melanins are produced by Candida albicans, Fonsecaea pedrosoi (Nosanchuk et al. 2015), flavins (polyketides) are obtained from Ashbya gossypii and Candida famata (Stahmann et al. 2000) and quinones are produced by Eutotium sp., Fusarium sp., Curvularia lunata, and Drechslera sp. (Torres et al. 2016). These pigments are utilized in food, cosmetics, textile and pharmaceutical industries.

In this study endophytic fungal strain capable of producing extracellular pigment was isolated form Teucrium stocksianum and optimum conditions for attaining maximum pigment yield were evaluated. Effect of temperature, $\mathrm{pH}$ and culture medium was determined. The pigment was extracted, purified and characterized. After purification the antimicrobial and antioxidant potential were estimated.

\section{Materials And Methods}

\section{Fungal isolation}

Endophytic fungi were isolated from a medicinal plant named as Teucrium stocksianum taken from district Bajaur, Khyber Pakhtunkhwa, Pakistan. Stem, leaves and wood of plant were placed under running tap water for 15 minutes and then cut into small pieces of 0.2-0.5 $\mu \mathrm{m}$ using sterile scalpel. The sample were sterilized with $70 \%$ ethanol solution for 3 minutes then with aqueous sodium hypo chloride (4 \% available chlorine) for 3-5 minutes followed by rinsing with $70 \%$ ethanol for 2-10 seconds and finally washed with double distilled water in laminar flow hood. Wood, leaves and roots sample were placed on sterilized SDA plates which are then incubated at $28{ }^{\circ} \mathrm{C}$ for 7 days. After that the appeared colonies were purified on SDA plates separately at the same conditions. Purified strains were preserved on SDA slants placed at $4{ }^{\circ} \mathrm{C}$ for short term preservation.

\section{Screening for pigment production}

Different strains were isolated from medicinal plant but only one strain named as N11 produced brown pigment on SDA plate. It was then inoculated in $200 \mathrm{ml}$ of Sabouraud dextrose broth. A mycelium plug of $5 \mathrm{~mm}$ in diameter was cut from the freshly grown plate with the help of sterilized scalpel and inoculated in $200 \mathrm{ml}$ of SDB in $500 \mathrm{ml}$ Erlenmeyer flask after being autoclaved at $121^{\circ} \mathrm{C}$ for 15 minutes. The inoculated flask was cultured in dark at $28{ }^{\circ} \mathrm{C}$ for ten to fourteen days with shaking at $150 \mathrm{rpm}$ in shaking incubator. 


\section{Identification of fungal strain}

\section{Morphological studies}

Conventionally morphological characters were used for tentative identification of fungal strains. Colony characters such as aerial mycelium, density and pigment production were recorded. Microscopic features of the fungus were observed by using a light microscope.

\section{Molecular identification}

Further molecular identification was done using 18S rRNA sequencing and homology analyses from the Database.

\section{Optimization of fungal pigment production}

\section{Fungal cultivation and pigment yield estimation}

Fungal mycelial plugs (3-5 mm in diameter) obtained from the margin of the fresh colony on SDA at 28 ${ }^{\circ} \mathrm{C}$ for 1 week was transferred into a $100 \mathrm{ml}$ of liquid medium in $250 \mathrm{ml}$ Erlenmeyer flask after being autoclaved at $121^{\circ} \mathrm{C}$ for $15 \mathrm{~min}$. Cultivation was performed in the dark at $28^{\circ} \mathrm{C}$ with shaking at $150 \mathrm{rpm}$ on a shaking incubator for ten to fourteen days. After cultivation the media was filtered, and pigment was estimated by using spectrophotometric analysis. The Optical density was measured at $660 \mathrm{~nm}$ (wavelength which represents the absorption maxima for orange-brown color). The pigment yield was estimated by converting OD into AU with method explained by (Palacio-Barrera et al. 2019). The following formula was used for conversion of optical density into AU

Formula for Absorbance Units:

$\mathrm{AU}=[\mathrm{Abs} \times \mathrm{Vfl}] / \mathrm{Vr}$

Where $\mathrm{AU}=\mathrm{Abs}$ rbance units

$\mathrm{V} f \mathrm{l}=$ Filtered volume and $\mathrm{Vr}=$ Volume read in spectrophotometer

\section{Biomass estimation}

After cultivation the mycelium was harvested by using pre weighed Whatman No. 1 paper and then dried at room temperature for 48 hours. After drying the dry cell weight of mycelium was measured and expressed as $\mathrm{mg} / \mathrm{ml}$ (Visalakchi and Muthumary 2010).

\section{Effect of liquid culture medium}

Three different media (Sabouraud Dextrose Broth (SDB), Potato Dextrose broth (PDB) and rice medium) were used for cultivation of fungal strain. After inoculation flasks were incubated in shaking incubator 
(150 rpm) at $28{ }^{\circ} \mathrm{C}$ for 21 days. The culture liquid medium that presented the highest yield of the pigment was selected for further experiments.

\section{Effect of temperature}

Inthis experiment, a fungal culture was inoculated in the selected liquid medium that had been obtained from previous experiments. $\mathrm{A} \mathrm{pH}$ value of 6.0 was adjusted by using $1 \mathrm{~N} \mathrm{HCl}$ and $1 \mathrm{~N} \mathrm{NaOH}$ and the culture was incubated at $20,25,30,35^{\circ} \mathrm{C}$ for 21 days with shaking at $150 \mathrm{rpm}$. The temperature that presented the highest yield of the pigment was selected for further experiments.

\section{Effect of initial pH}

The initial $\mathrm{pH}$ of the selected suitable components of the medium that was from previous experiments was adjusted from 5.0 to 8.0 with the help of $1 \mathrm{~N} \mathrm{HCl}$ and $1 \mathrm{~N} \mathrm{NaOH}$ in each flask before being autoclaving. After inoculation, cultures were incubated at temperature that presented the highest pigment yield for 21 days. The initial $\mathrm{pH}$ of culture media that presented the highest yield of the pigment was selected for further experiments.

\section{Large scale cultivation and extraction}

For this experiment $2000 \mathrm{ml}$ Erlenmeyer flasks containing $1000 \mathrm{ml}$ of optimized medium and $\mathrm{pH}$ was autoclaved. Five fungal mycelium plugs of 3-5 $\mathrm{mm}$ obtained from the edges of growing fungal colony on SDA were transferred to the autoclaved medium and the flask was incubated at optimized temperature with $150 \mathrm{rpm}$ rotation in a rotary shaker.

After fermentation the medium was filtered through Whatman No. 1 paper and the filtered medium was extracted using two volumes of ethyl acetate according to the method described by (Suwannarach et al. 2019a). After extraction the ethyl acetate fraction was evaporated in a rotary evaporator and crude extract obtained was saved for further experimentation.

\section{Fungal pigment purification by Normal phase column chromatography}

The purification of crude pigment was carried out by using normal phase column chromatography followed by Thin Layer Chromatography (TLC). The crude pigment was dissolved in ethyl acetate and mixed with silica gel which is used as a stationary phase. The column (column size $45 \times 2.6 \mathrm{~cm}$ ) was filled with prepared silica gel and the pigment was eluted by using different solvents ( $\mathrm{N}$-hexane, ethyl acetate, methanol, acetone and acetonitrile) in different ratios. The eluted fractions were examined by TLC in pre-coated TLC plates in the same mobile phase to check the purity of fractions. Retention factor $\left(R_{f}\right)$ value of each sample was calculated as described by (Gupta et al. 2019).

All the fractions collected were subjected to TLC and the fractions having same $R_{f}$ values were combined, and the solvent was evaporated to obtain the purified pigments in dried form. 


\section{Fourier-transform infrared spectroscopy (FT-IR) analysis of the purified pigment}

Orange-brown pigments isolated from Aspergillus sp. N11 were analyzed by FTIR (Bruker, Tensor 27, equipped with ZnSe ATR) spectrophotometer in the range of $400-4000 \mathrm{~cm}^{-1}$ wavelength. Approximately $2 \mu \mathrm{g}$ of pigments were placed on a diamond window of the spectrophotometer. The FTIR spectrum was used to identify different functional groups present in the pigments.

\section{Determination of Antimicrobial activity of purified pigment}

The antimicrobial activity of purified pigment was evaluated against gram positive Staphylococcus aureus (ATCC 25923), gram negative Pseudomonas aeruginosa (ATCC 27853) and Candida albicans (ATCC 10231)strains were tested by using agar well diffusion method described earlier by (Walia et al. 2020). Bacterial test strains were inoculated in nutrient broth and incubated for 12-18 hours at $37^{\circ} \mathrm{C}$ and $150 \mathrm{rpm}$ in shaking incubator while fungal strains were inoculated in Sabouraud dextrose broth and incubated at $30{ }^{\circ} \mathrm{Cfor} 48-72$ hours at $150 \mathrm{rpm}$ in a shaking incubator. Inoculum equal to 0.5 McFarland of each strain was prepared. Bacterial inoculum was spread on Muller Hinton plates and fungal inoculum was spread on SDA plates by using sterile swabs. Wells of $6 \mathrm{~mm}$ diameter were made aseptically by using a sterile cork borer. $100 \mu \mathrm{l}$ of purified pigmented fractions having a concentration of $1 \mathrm{mg} / \mathrm{ml}$ were added in wells aseptically along the solvent ethyl acetate as negative control, levofloxacin $(10 \mu \mathrm{g})$ for bacterial strains and nystatin $(50 \mu \mathrm{g})$ for fungal strains as positive control. Then plates were incubated at $37{ }^{\circ} \mathrm{C}$ for bacteria and at $30^{\circ} \mathrm{C}$ for fungi. when incubation period was completed, each plate was examined for zone of inhibition. The zone of inhibition was reported in milli- meters $(\mathrm{mm})$.

\section{Determination of antioxidant activity by DPPH assay}

DPPH (2,2-diphenyl-1-picrylhydrazyl) is a stable free radicle having red color in solution form. The antioxidants neutralize this free radicle and change its color to yellow. This method is used widely to check the scavenging of free radicles (Devi 2018). Purified pigment was dissolved in methanol to attain the conc. of $200 \mu \mathrm{g} / \mathrm{ml}$ and added to $1 \mathrm{ml}$ of $3 \mathrm{mM}$ DPPH solution and incubated at $37^{\circ} \mathrm{C}$ for $30-45$ minutes. Ascorbic acid $(1000 \mu \mathrm{g} / \mathrm{ml})$ was taken as positive control while methanol and DPPH solution was taken as negative control. After incubation OD was taken at $517 \mathrm{~nm}$ and \%inhibition was calculated by using the formula given below:

\%Inhibition $=\left(A_{c}-A_{s} / A_{c}\right) \times 100$

Where $A_{C}=$ absorbance of control and $A_{S}=$ absorbance of pigment

\section{Results}

\section{Isolation and morphological identification of fungi}

Eleven isolates were obtained from different parts of the plant but only one isolate N11 was able to produce extra cellular orange-brown pigment. Colony of N11 isolate on SDA grew to 70-75 mm at 
$30{ }^{\circ} \mathrm{C}$ in dark after 7-9 days. Colonies were flat with entire edge, floccose having white or cream-colored aerial mycelium producing orange-brown pigment and reverse was straw colored [Fig. 1]. Based on these findings the isolate is identified as Aspergillus sp. (Nyongesa et al. 2015).

Molecular identification using $18 \mathrm{~S}$ rDNA sequencing and phylogenetic identification showed the strain N11 is related to Aspergillus niger. The evolutionary history was inferred using the Neighbor-joining method. The optimal tree is shown in Fig. 2. The percentage replicate trees in which the associated taxa clustered together in the bootstrap test (100 replicates) are shown next to the branches. The evolutionary distance was computed using the maximum composing likelihood method and are in the units of the number of base substituents per site. This analysis involved 9 nucleotide sequences. Codon positions included were 1ST+2nd+3rd+noncoding. All ambiguous positions were removed for each sequence pair (Pairwise deletion option). There was a total of 876 positions in the final dataset. Evolutionary analysis was conducted in MEGA X [Fig. 2].

\section{Optimization of fungal pigments}

The orange-brown pigment gave maximum absorbance at $660 \mathrm{~nm}$ as reported by (Velmurugan et al. 2010). So, total pigment yield was estimated at $660 \mathrm{~nm}$ and converted into AU (Absorbance units). Pigment yield and fungal biomass produced by Aspergillus sp. N11 in different mediums is shown in Fig. 3a. Results indicate that highest biomass of $9.7 \pm 0.5 \mathrm{mg} / \mathrm{ml}$ and pigment yield of ( $85.5 \mathrm{AU} \pm 0.5 \mathrm{AU}$ ) was observed in PDB while no pigment was produced in rice medium. Temperature also affects fungal growth and its pigment production as shown in Fig .3b. The temperature selected for present study ranges between $20^{\circ} \mathrm{C}$ to $35^{\circ} \mathrm{C}$ for optimization of pigments from endophytic strains. Aspergillus sp. $\mathrm{N} 11$ gave maximum pigment yield of $(85.5 \mathrm{AU})$ at $30^{\circ} \mathrm{C}$ followed by $35^{\circ} \mathrm{C}(56.5 \mathrm{AU})$. Moreover, the results showed that initial pH also affects fungal growth and metabolism as the highest pigment yield of $289.25 \mathrm{AU}$ was observed at pH 5 rather than pH 6,7 and 8 shown in Fig. 3c.

\section{Fungal pigment extraction and purification}

The pigment production was evaluated by growing Aspergillus sp. N11 in a $2000 \mathrm{ml}$ Erlenmeyer flask having $1000 \mathrm{ml} \mathrm{PDB}$ medium at optimized conditions $\left(\mathrm{pH} \mathrm{5}\right.$, temperature $\left.30^{\circ} \mathrm{C}\right)$. After 7-10 days of inoculation the liquid culture was filtered, and filtrate was extracted with double volume of ethyl acetate. After extraction $350 \mathrm{mg} / \mathrm{L}$ of crude pigment was obtained. The crude pigment extract was purified by using column chromatography. The crude extract was dissolved in ethyl acetate and mixed with silica gel. Silica gel is used as stationary phase because it is an inert substance and do not react with the samples. Samples retain their structural and chemical properties while passing through silica (Basnet et al. 2019). The pigment was eluted with different solvents. TLC of each pigmented fraction was carried out and the fraction having same $R_{f}$ value were pooled and concentrated as shown in Table 1 . The result of TLC shows that F10, F21 and F34 have $R_{f}$ values of $0.88,0.77$ and 0.81 respectively. It was reported in different studies that compounds showing $R_{f}$ values ranging between $0.75-0.85$ are astaxanthin 
diesters (Minyuk and Solovchenko 2018), while compounds having $R_{f}$ value of 0.87 are echinenone (Elumalai et al. 2014).

\section{FTIR analysis of pure pigment}

FTIR analysis of three different fractions of Aspergillus sp. N11 were observed. Fraction 10 (yellow) of Aspergillus sp. N11 showed peaks at $2924 \mathrm{~cm}-1$ representing C-H stretching (Alkane), peak at $2854 \mathrm{~cm}-1$ shows presence of $\mathrm{C}-\mathrm{H}$ (methyl group) and peaks $1649 \mathrm{~cm}-1$ represents $\mathrm{C}-\mathrm{H}$ stretching in its structure shown in Fig 4a. Fraction 21(brown) of Aspergillus sp. N11 shows peaks at $3339 \mathrm{~cm}-1$ representing C-H stretching (alkyl), peaks at $2986 \mathrm{~cm}-1$ shows the presence of C-H bond (methyl group), peaks at $1639 \mathrm{~cm}-$ 1 represents $\mathrm{C}=0$ stretching (ketones), peaks at $1373 \mathrm{~cm}-1$ represents $\mathrm{C}-\mathrm{F}$ stretching (fluoro compounds), $\mathrm{O}-\mathrm{H}$ bending (phenols) and peaks at $1043 \mathrm{~cm}-1$ represents $\mathrm{S}=0$ stretching (sulphates) shown in Fig. 4b. Fraction 34 (brown) of Aspergillus sp. N11 shows peaks at $2984 \mathrm{~cm}-1$ shows presence of C-H (methyl group), peaks at $1744 \mathrm{~cm}-1$ representing $\mathrm{C}=0$ stretching (cyclopentanone), peaks at $1736 \mathrm{~cm}-1$ represent $\mathrm{C}=0$ stretching (aldehydes) and peaks at $1372 \mathrm{~cm}-1$ represents $\mathrm{S}=0$ stretching (sulfonates) as shown in Fig. 4c. The presence of hydroxyl $(-\mathrm{OH})$ and ketone $(\mathrm{C}=0)$ groups confirms that these pigments can be astaxanthins as these groups can react and change their forms. Methyl groups (C-H) confirms the presence of aliphatic chains and alkenes $(C-0, C=0)$ confirms the presence of esters (Elumalai et al. 2014, Yoo et al. 2016).

\section{Antimicrobial activity of purified pigments}

The antimicrobial activity of purified fractions (F10, F21 and F34) were tested against gram positive Staphylococcus aureus (ATCC 25923) Fig. 5a, gram negative Pseudomonas aeruginosa (ATCC 27853) Fig 5b and Candida albicans (ATCC 10231) Fig. 5c strains. The maximum zone of inhibition of $40 \mathrm{~mm}$ was shown by Fraction 34 against Gram positive $S$. aureus while for Gram negative $P$. aeruginosa maximum zone of $50 \mathrm{~mm}$ was also shown by Fraction 34. On the other hand, Fraction 34 showed maximum antifungal activity of $20 \mathrm{~mm}$ against $C$. albicans. The graphical representation is shown in Fig. $5 d$.

\section{Antioxidant activity of purified pigment}

DPPH assay was used to determine the antioxidant potential of purified pigment obtained from Aspergillus $s p$. N11 the results indicate that maximum scavenging activity of $67 \%$ was shown by Fraction 10. Others fractions of Aspergillus sp. N11 such as F34 exhibits $64 \%$ and F21 has $4 \%$ antioxidant activity as shown in Fig. 6 . The scavenging activity of positive control of ascorbic acid is 86 $\%$ which reveals that the pigmented fractions have less activity as compared to positive control.

\section{Discussion}

Endophytic fungi are a potential source of novel secondary metabolites such as pigments, antimicrobial compounds and antioxidants(Pagano and Dhar 2015; Qiu et al. 2010; Sibero et al. 2017). In this study an 
endophytic Aspergillus sp. isolated from Teucrium stocksianum produced an orange-brown extracellular pigment and different studies suggest that genus Aspergillus produces diverse extracellular pigments of brown, yellow (Narendrababu and Shishupala 2017) and black color (melanins) (Pal et al. 2014; Suwannarach et al. 2019b).

In this study the optimum conditions for pigment and biomass production from Aspergillus sp. N11 were determined. The isolate Aspergillus sp. N11 produce maximum pigment in PDB at pH 5 and temperature of $30{ }^{\circ} \mathrm{C}$ with rotation of $150 \mathrm{rpm}$ while incubation for 7-10 days. These results were supported by the study of (Lebeau et al. 2017) in which it was reported that Talaromyces sp. produced highest biomass of $5.5 \mathrm{mg} / \mathrm{ml}$ in PDB as compared to other mediums and (Mishra et al. 2021) reported that maximum pigment of 98.4 AU was produced in PDB. This media favors biomass production due to its nutrient rich composition that enhances the growth of fungi and contains a complex nitrogen and carbon source which favors extracellular pigment production. In submerged fermentation addition of an amino acid or another complex nitrogen source impacts the types and excretion of pigments in media. Amino acid metabolism and limited nitrogen source increase pigment production because the surplus energy or carbon source is not utilized for protein synthesis and is available for other metabolisms (Rodríguez-Ortiz et al. 2009).

Abiotic factors such as temperature and $\mathrm{pH}$ also affect pigment production and fungal growth. Environmental temperature effects the normal metabolic functioning of fungi. Variation in incubation temperature can affect mycelial growth and metabolic reactions. The alteration in growth temperature changes the production pathways of secondary metabolites such as low temperature favors production of $ß$-carotene and blocked the pathway responsible for torulene production in different species. Moreover, temperature change also affects the type and quantity of pigment produced (Avalos and Corrochano 2013). Other finding also support the obtained results as Monascus purpureus produces maximum red pigment at $30{ }^{\circ} \mathrm{C}$ (Nimnoi and Lumyong 2011) and Fusarium moniliforme produces highest yield at 28 ${ }^{\circ} \mathrm{C}$ (Stanly Pradeep and Pradeep 2013). Initial pH is also an important factor in pigmentation as it affects normal metabolism of mycelium. Change in $\mathrm{pH}$ during growth occurs due to nitrogen and carbon metabolism. Change in $\mathrm{pH}$ primarily effects oxidation reduction reaction of the cell and in result the oxidative and redox flux of main energy carrying molecule ATP (Adenosine triphosphate) is altered. This change in ATP influx effects cellular metabolism and the formation of end-products of metabolic pathways. So, $\mathrm{pH}$ must be regulated and optimized for proper metabolism which will lead to normal pigment and secondary metabolite production (Méndez et al. 2011). Parul et al. (2020) reported that Talaromyces purpureogenus also produced maximum pigment at pH 5. Nigrospora aurantiaca also produces maximum red pigment at pH 5 (Suwannarach et al. 2019a).

The fungal pigments obtained were characterized based on TLC and FTIR results to be astaxanthins which are a class of carotenoids having oxygen in their structure. Pharmaceutical applications such as antibacterial, antifungal and antioxidant activity of purified pigments were evaluated as carotenoids possess bioactive properties. Astaxanthins can suppress the expression of some cytokines such as IL-6, TNF- $\alpha$ and IL-1 $\beta$ and exhibit anti-inflammatory activity (Monsur 2011). Astaxanthin possess antiaging 
properties and can repair UV induced skin damage and wrinkles. Moreover due to the excellent antioxidant activity and ability to cross blood brain barrier it has wide applications in treatment of neurodegenerative diseases (Kowsalya et al. 2019). Some carotenoids such as astaxanthin, lutein and $\beta$ cryptoxanthin are used in prevention of cardiovascular diseases as they oxidize LDL and reduce levels of HDL(Bhatt and Patel 2020). In the ongoing study, antibacterial activity of purified pigments was analyzed against Staphylococcus aureus and Pseudomonas aeruginosa. (Karpiński and Adamczak 2019) reported that fucoxanthin carotenoid also exhibited activity against both these isolates. Results were supported by studies of (Madhukar 2017) and (Saravanan et al. 2020) in which different purified fungal pigments showed $26 \mathrm{~mm}$ and $8 \mathrm{~mm}$ zone of inhibition against $S$. aureus. (Łopusiewicz 2018) reported that melanin pigment from Armillaria mellea gave activity against $P$. aeruginosa with zones of inhibitions varying between $12 \mathrm{~mm}$ to $15 \mathrm{~mm}$.

Oxidation reaction leads to the formation of free radicals called reactive oxygen species (ROS). These free radicals can cause cell damage by participating in cellular reactions leading to electrolyte imbalance. The excessive oxidation stress can cause several diseases including diabetes, Alzheimer's disease, cancer, hepatic and liver damage and other neurological disorders (Balin and Allen 2018). Pigments obtained from Aspergillus sp. N11 having antioxidant activity can neutralize these free radicals and thus can be used in treatment of different diseases associated with ROS. Different studies reported pigments having antioxidant potential. Aspergillus tamarii produced pigments showing antioxidant activity of $70 \%$ (Fariq et al. 2019) and Veronicastrum latifolium purified flavonoids have 55\% antioxidant activity (Yin et al. 2019). Natural colorants are gaining public interest due to their health benefits and environmentalfriendly nature. Micro-organisms are the main source of natural pigments having various applications in food, textile, cosmetic and pharmaceutical industries. In this study an endophytic fungus producing orange-brown pigment was isolated from Teucrium stocksianum. The fungus was identified based on morphological characters as Aspergillus sp. N11. Abiotic factors such as liquid medium, temperature and $\mathrm{pH}$ were optimized, and pigment was extracted using ethyl acetate. The extracted pigment was purified and characterized based on TLC and FTIR results. According to TLC bands and functional groups present the pigment is identified as astaxanthin. The astaxanthin pigment showed antibacterial, antifungal and antioxidant activity. Other techniques such as HPLC, LC-MS and GC-MS can be used for further characterization of the purified pigment.

\section{Abbreviations}




\begin{tabular}{ll} 
SDB & Sabaroud dextrose agar \\
\hline PDB & Potato dextrose agar \\
\hline TLC & Thin layer chromatography \\
\hline FTIR & Fourier-transform infrared spectroscopy \\
\hline ATP & Adinosine tri phosphate \\
\hline ROS & Reactive oxygen spicies \\
\hline UV & Ultra voilet \\
\hline HPLC & High performance liquid chromatography \\
\hline LCMS & Liquid chromatography Mass spectroscopy \\
\hline GCMS & Gas chromatography Mass spectrosopy \\
\hline LDL & Low density Lipoprotiens \\
\hline HDL & High density Lipoprotiens \\
\hline Mm & Milimeter \\
\hline Ml & Mili liter \\
\hline $\boldsymbol{\mu l}$ & Micro liter \\
\hline $\boldsymbol{\mu g}$ & Micro gram \\
\hline Mg & Mili gram \\
\hline $\boldsymbol{\mu g}$ & Micrograms \\
\hline${ }^{\circ} \mathrm{C}$ & Degree centigrade \\
\hline$\%$ & Percentage \\
\hline
\end{tabular}

\section{Declarations}

\section{Funding}

No funding from externals is received for this research.

Competing interests:

The authors declare that they have no competing interests.

\section{Authors contributions}


MA and SA, Conception, and study design, MA, AU, HJ and QA, carry out experimental work of study, MA, $\mathrm{AH}$, and IU testing and data analysis of the study, SA, Supervision, MA, draft the manuscript, MA, AU and $\mathrm{SA}$, revised the manuscript. All authors read and approved the final manuscript.

\section{Availability of data and material:}

The data used to support the findings of this study are available from the corresponding author upon request.

\section{Ethics approval and consent to participate:}

This article does not contain any human and animal studies performed by any of the authors.

\section{Consent to participate}

Not applicable.

\section{Consent to publication:}

Not applicable.

\section{Acknowledgments}

Not applicable

\section{Author's information:}

Madeha Ashfaq ${ }^{1}$, Qurban Ali ${ }^{1}$, Abdul Haleem ${ }^{1}$, Hira javed ${ }^{1}$, Aman Ullah ${ }^{1}$, Aiman Umar ${ }^{1}$, Irfan Ullah ${ }^{1}$, Safia Ahmed ${ }^{1 *}$

1 Department of Microbiology, Quaid-i-Azam University, Islamabad 45320, Pakistan

Madeha Ashfaq: madeha12ashfaq@gmail.com

Qurban Ali: Qurbanalip@yahoo.com

Abdul Haleem: haleem_halim@yahoo.com

Hira Javed: h.jawedbhatti@gmail.com

Aman Ullah: amanwzir@gmail.com

Aiman Umar: aimanumer3@gmail.com

Irfan Ullah: irfanmuhsin.bjr@gmail.com

*Corresponding Author(s): 


\section{Prof. Dr. Safia Ahmed}

Department of Microbiology, Faculty of biological sciences, Quaid-i-Azam University, Islamabad 45320, Pakistan

Email: safiamrl@yahoo.com Phone+92-51-90643009

\section{Endnotes}

Not applicable

\section{References}

1. Aberoumand A (2011) A review article on edible pigments properties and sources as natural biocolorants in foodstuff and food industry. Journal of Dairy \& Food Sciences 6(1):71-78

2. Akilandeswari P, Pradeep BV (2016) Exploration of industrially important pigments from soil fungi. Applied Microbiology and Biotechnology 100(4):1631-1643 doi:10.1007/s00253-015-7231-8

3. Avalos J, Corrochano LM (2013) Carotenoid biosynthesis in Neurospora. Neurospora: Genomics and Molecular Biology, Kasbekar, DP, McCluskey, K, Eds:227-241

4. Avalos J, Limón MC (2015) Biological roles of fungal carotenoids. Current Genetics 61(3):309-324

5. Balin AK, Allen RG (2018) Oxidative stress and aging. Encyclopedia of Endocrine Diseases 4(9):659663 doi:10.1016/B978-0-12-801238-3.03872-1

6. Basnet BB, Liu L, Zhao W, Liu R, Ma K, Bao L, Ren J, Wei X, Yu H, Wei J, Liu H (2019) New 1, 2naphthoquinone-derived pigments from the mycobiont of lichen Trypethelium eluteriae Sprengel. Natural Product Research 33(14):2044-2050 doi:10.1080/14786419.2018.1484458

7. Bhatt T, Patel K (2020) Carotenoids: Potent to Prevent Diseases Review. Natural Products and Bioprospecting 10(3):109-117 doi:10.1007/s13659-020-00244-2

8. Bisht G, Srivastava S, Kulshreshtha R, Sourirajan A, Baumler DJ, Dev K (2020) Applications of red pigments from psychrophilic Rhodonellum psychrophilum GL8 in health, food and antimicrobial finishes on textiles. Process Biochemistry 94:15-29 doi:10.1016/j.procbio.2020.03.021

9. Chandi GK, Gill BS (2011) Production and characterization of microbial carotenoids as an alternative to synthetic colors: A review. International Journal of Food Properties 14(3):503-513 doi:10.1080/10942910903256956

10. da Silva MHR, Cueva-Yesquén LG, Júnior SB, Garcia VL, Sartoratto A, de Angelis DdF, de Angelis DA (2020) Endophytic fungi from Passiflora incarnata: an antioxidant compound source. Archives of Microbiology 202(10):2779-2789 doi:10.1007/s00203-020-02001-y

11. Devi R (2018) ANTIMICROBIAL , ANTIOXIDANT AND CYTOTOXICITY ACTIVITY OF PIGMENT European of Biomedical AND Pharmaceutical sciences. (January 2017)

12. Elumalai S, Santhose BI, Kanna GR (2014) Extraction of carotenoid and thin layer chromatography (TLC), GC-MS , FT-IR and HPLC analysis of pharmaceutically important pigment astaxanthin from a 
new strain of Haematococcus pluvialis. Weekly Science Research Journal 2(8):1-14

13. Fariq A, Yasmin A, Jamil M (2019) Production, characterization and antimicrobial activities of biopigments by Aquisalibacillus elongatus MB592, Salinicoccus sesuvii MB597, and Halomonas aquamarina MB598 isolated from Khewra Salt Range, Pakistan. Extremophiles 23(4):435-449 doi:10.1007/s00792-019-01095-7

14. Gupta N, Poddar K, Sarkar D, Kumari N, Padhan B, Sarkar A (2019) Fruit waste management by pigment production and utilization of residual as bioadsorbent. Journal of Environmental Management 244(May):138-143 doi:10.1016/j.jenvman.2019.05.055

15. Julistiono H, Setianingrum N, Mulyadi, Putri DTR, Zalinda RY, Ramadhani I, Hasan AEZ (2021) Antioxidant and antimicrobial activities of dark pigment extracted from phomopsis sp., an endophytic fungi of annona muricata. Pharmacologyonline 2:1026-1032

16. Karpiński TM, Adamczak A (2019) Fucoxanthin-an antibacterial carotenoid. Antioxidants 8(8):1-8 doi:10.3390/antiox8080239

17. Khorasanizadeh MH, Monsef R, Amiri O, Amiri M, Salavati-Niasari M (2019) Sonochemical-assisted route for synthesis of spherical shaped holmium vanadate nanocatalyst for polluted waste water treatment. Ultrasonics sonochemistry 58:104686-104686

18. Kobylewski S, Jacobson MF (2012) Toxicology of food dyes. International journal of occupational and environmental health 18(3):220-246

19. Kowsalya K, Vidya N, Vijayalakshmi V, Arun M (2019) Super Nutritive Marine Astaxanthin, an Effectual Dietary Carotenoid for Neurodegenerative Diseases. International Research Journal of Multidisciplinary Technovation(August):115-124 doi:10.34256/irjmtcon14

20. Lebeau J, Venkatachalam M, Fouillaud M, Petit T, Vinale F, Dufossé L, Caro Y (2017) Production and new extraction method of polyketide red pigments produced by ascomycetous fungi from terrestrial and marine habitats. Journal of Fungi 3(3) doi:10.3390/jof3030034

21. Łopusiewicz $\measuredangle$ (2018) The isolation, purification and analysis of the melanin pigment extracted from Armillaria mellea rhizomorphs. Wolrd Scientific News 100(May):135-153

22. Madhukar CV (2017) All Rights Reserved WJES @ 2014 Available Online at : www.environmentaljournals.org Antimicrobial and Antioxidant potentials of Carotenoid Pigment Produced by Indigenous Novel Soil Isolate Rhodococcus k roppenstedtii. 10(1):29-34

23. McCann D, Barrett A, Cooper A, Crumpler D, Dalen L, Grimshaw K, Kitchin E, Lok K, Porteous L, Prince E, Sonuga-Barke E, Warner JO, Stevenson J (2007) Food additives and hyperactive behaviour in 3year-old and 8/9-year-old children in the community: a randomised, double-blinded, placebocontrolled trial. Lancet 370(9598):1560-1567 doi:10.1016/S0140-6736(07)61306-3

24. Méndez A, Pérez C, Montañéz JC, Martínez G, Aguilar CN (2011) Red pigment production by Penicillium purpurogenum $\mathrm{GH} 2$ is influenced by $\mathrm{pH}$ and temperature. Journal of Zhejiang University Science B 12(12):961-968

25. Menezes BS, Solidade LS, Conceição AA, Santos Junior MN, Leal PL, de Brito ES, Canuto KM, Mendonça S, de Siqueira FG, Marques LM (2020) Pigment production by Fusarium solani 
BRM054066 and determination of antioxidant and anti-inflammatory properties. AMB Express 10(1) doi:10.1186/s13568-020-01054-y

26. Meruvu H, Dos Santos JC (2021) Colors of life: a review on fungal pigments. Critical Reviews in Biotechnology:1-25

27. Minyuk GS, Solovchenko AE (2018) Express analysis of microalgal secondary carotenoids by TLC and UV-Vis spectroscopy. Methods in Molecular Biology 1852:73-95 doi:10.1007/978-1-4939-87429_4

28. Mishra RC, Kalra R, Dilawari R, Deshmukh SK, Barrow CJ, Goel M (2021) Characterization of an Endophytic Strain Talaromyces assiutensis, CPEF04 With Evaluation of Production Medium for Extracellular Red Pigments Having Antimicrobial and Anticancer Properties. Frontiers in Microbiology 12(August):1-16 doi:10.3389/fmicb.2021.665702

29. Monsur HA (2011) Anti-inflammatory compounds of macro algae origin: A review. Journal of Medicinal Plants Research 5(33):7146-7154

30. Narendrababu B, Shishupala S (2017) Spectrophotometric detection of Pigments from Aspergillus and Penicillium isolates. Journal of Applied Biology and Biotechnology 5(01):053-058 doi:10.7324/jabb.2017.50109

31. Narsing Rao MP, Xiao M, Li WJ (2017) Fungal and bacterial pigments: Secondary metabolites with wide applications. Frontiers in Microbiology 8(JUN):1-13 doi:10.3389/fmicb.2017.01113

32. Nimnoi P, Lumyong S (2011) Improving Solid-State Fermentation of Monascus purpureus on Agricultural Products for Pigment Production. Food and Bioprocess Technology 4(8):1384-1390 doi:10.1007/s11947-009-0233-8

33. Nosanchuk JD, Stark RE, Casadevall A (2015) Fungal melanin: what do we know about structure? Frontiers in microbiology 6:1463-1463

34. Nyongesa BW, Okoth S, Ayugi V (2015) Identification Key for Aspergillus Species Isolated from Maize and Soil of Nandi County, Kenya. Advances in Microbiology 05(04):205-229 doi:10.4236/aim.2015.54020

35. Pagano MC, Dhar PP (2015) Fungal pigments: an overview. Fungal biomolecules: sources, applications and recent developments 13:173-179

36. Pal AK, Gajjar DU, Vasavada AR (2014) DOPA and DHN pathway orchestrate melanin synthesis in Aspergillus species. Medical Mycology 52(1):10-18 doi:10.3109/13693786.2013.826879

37. Palacio-Barrera AM, Areiza D, Zapata P, Atehortúa L, Correa C, Peñuela-Vásquez M (2019) Induction of pigment production through media composition, abiotic and biotic factors in two filamentous fungi. Biotechnology Reports 21(2018):e00308-e00308 doi:10.1016/j.btre.2019.e00308

38. Parul, Thiyam G, Dufossé L, Sharma AK (2020) Characterization of Talaromyces purpureogenus strain $\mathrm{F}$ extrolites and development of production medium for extracellular pigments enriched with antioxidant properties. Food and Bioproducts Processing 124:143-158 doi:10.1016/j.fbp.2020.08.012 
39. Qiu M, Xie R, Shi Y, Chen H, Wen Y, Gao Y, Hu X (2010) Isolation and identification of endophytic fungus SX01, a red pigment producer from Ginkgo biloba L. World Journal of Microbiology and Biotechnology 26(6):993-998

40. Rodríguez-Ortiz R, Limón MC, Avalos J (2009) Regulation of carotenogenesis and secondary metabolism by nitrogen in wild-type Fusarium fujikuroi and carotenoid-overproducing mutants. Applied and Environmental Microbiology 75(2):405-413 doi:10.1128/AEM.01089-08

41. Saravanan A, Jayasree R, Kumar PS, Varjani S, Hemavathy RV, Jeevanantham S, Yaashikaa PR (2020) Production of pigment using Aspergillus tamarii: New potentials for synthesizing natural metabolites. Environmental Technology and Innovation 19:100967-100967 doi:10.1016/j.eti.2020.100967

42. Sibero MT, Sahara R, Syafiqoh N, Tarman K (2017) Antibacterial activity of red pigment isolated from coastal endophytic fungi against multi-drug resistant bacteria. BIOTROPIA-The Southeast Asian Journal of Tropical Biology 24(2):161-172

43. Siva R (2017) in India Status of natural dyes and dye-yielding. Current Science 92(7):916-925

44. Stahmann KP, Revuelta JL, Seulberger H (2000) Three biotechnical processes using Ashbya gossypii, Candida famata, or Bacillus subtilis compete with chemical riboflavin production. Applied Microbiology and Biotechnology 53(5):509-516 doi:10.1007/s002530051649

45. Stanly Pradeep F, Pradeep BV (2013) Optimization of pigment and biomass production from Fusarium moniliforme under submerged fermentation conditions. International Journal of Pharmacy and Pharmaceutical Sciences 5(SUPPL 3):526-535

46. Suwannarach N, Kumla J, Nishizaki Y, Sugimoto N, Meerak J, Matsui K, Lumyong S (2019a) Optimization and characterization of red pigment production from an endophytic fungus, Nigrospora aurantiaca CMU-ZY2045, and its potential source of natural dye for use in textile dyeing. Applied microbiology and biotechnology 103(17):6973-6987

47. Suwannarach N, Kumla J, Watanabe B, Matsui K, Lumyong S (2019b) Characterization of melanin and optimal conditions for pigment production by an endophytic fungus, Spissiomyces endophytica SDBR-CMU319. PLoS ONE 14(9):1-15 doi:10.1371/journal.pone.0222187

48. Tang Z, Wang Y, Yang J, Xiao Y, Cai Y, Wan Y, Chen H, Yao H, Shan Z, Li C, Wang G (2020) Isolation and identification of flavonoid-producing endophytic fungi from medicinal plant Conyza blinii H.Lév that exhibit higher antioxidant and antibacterial activities. PeerJ 2020(4) doi:10.7717/peerj.8978

49. Tkaczyk A, Mitrowska K, Posyniak A (2020) Synthetic organic dyes as contaminants of the aquatic environment and their implications for ecosystems: A review. Science of The Total Environment 717:137222-137222

50. Torres FAE, Zaccarim BR, de Lencastre Novaes LC, Jozala AF, Santos CAd, Teixeira MFS, SantosEbinuma VC (2016) Natural colorants from filamentous fungi. Applied Microbiology and Biotechnology 100(6):2511-2521 doi:10.1007/s00253-015-7274-x

51. Velmurugan P, Kim MJ, Park JS, Karthikeyan K, Lakshmanaperumalsamy P, Lee KJ, Park YJ, Oh BT (2010) Dyeing of cotton yarn with five water soluble fungal pigments obtained from five fungi. Fibers 
and Polymers 11(4):598-605 doi:10.1007/s12221-010-0598-5

52. Venil C (2009) An insightful overview on microbial pigment, prodigiosin. Electronic Journal of ... $5(3): 49-61$

53. Visalakchi S, Muthumary J (2010) Antimicrobial activity of the new endophytic Monodictys castaneae SVJM139 pigment and its optimization. African Journal of Microbiology Research 4(1):38-44

54. Walia S, Mukhia S, Bhatt V, Kumar R, Kumar R (2020) Variability in chemical composition and antimicrobial activity of Tagetes minuta L. essential oil collected from different locations of Himalaya. Industrial Crops and Products 150(6):112449-112449 doi:10.1016/j.indcrop.2020.112449

55. Yin L, Han H, Zheng X, Wang G, Li Y, Wang W (2019) Flavonoids analysis and antioxidant, antimicrobial, and anti-inflammatory activities of crude and purified extracts from Veronicastrum latifolium. Industrial Crops and Products 137(June):652-661 doi:10.1016/j.indcrop.2019.04.007

56. Yoo AY, Alnaeeli M, Park JK (2016) Production control and characterization of antibacterial carotenoids from the yeast Rhodotorula mucilaginosa AY-01. Process Biochemistry 51(4):463-473 doi:10.1016/j.procbio.2016.01.008

\section{Tables}

Table 1 Silica gel column chromatography elution profile.

\begin{tabular}{|llll|}
\hline Solvent & Fraction no. & Weight of extract & $\mathbf{R}_{\mathbf{f}}$ value \\
\hline N-hexane: Ethyl Acetate & F10-F20 (yellow) & $85 \mathrm{mg}$ & 0.88 \\
\hline Ethyl acetate: Methanol (25:75) & F21-24 (light brown) & $78 \mathrm{mg}$ & 0.77 \\
\hline Acetonitrile & F34 (orange-brown) & $20 \mathrm{mg}$ & 0.81 \\
\hline
\end{tabular}

\section{Figures}




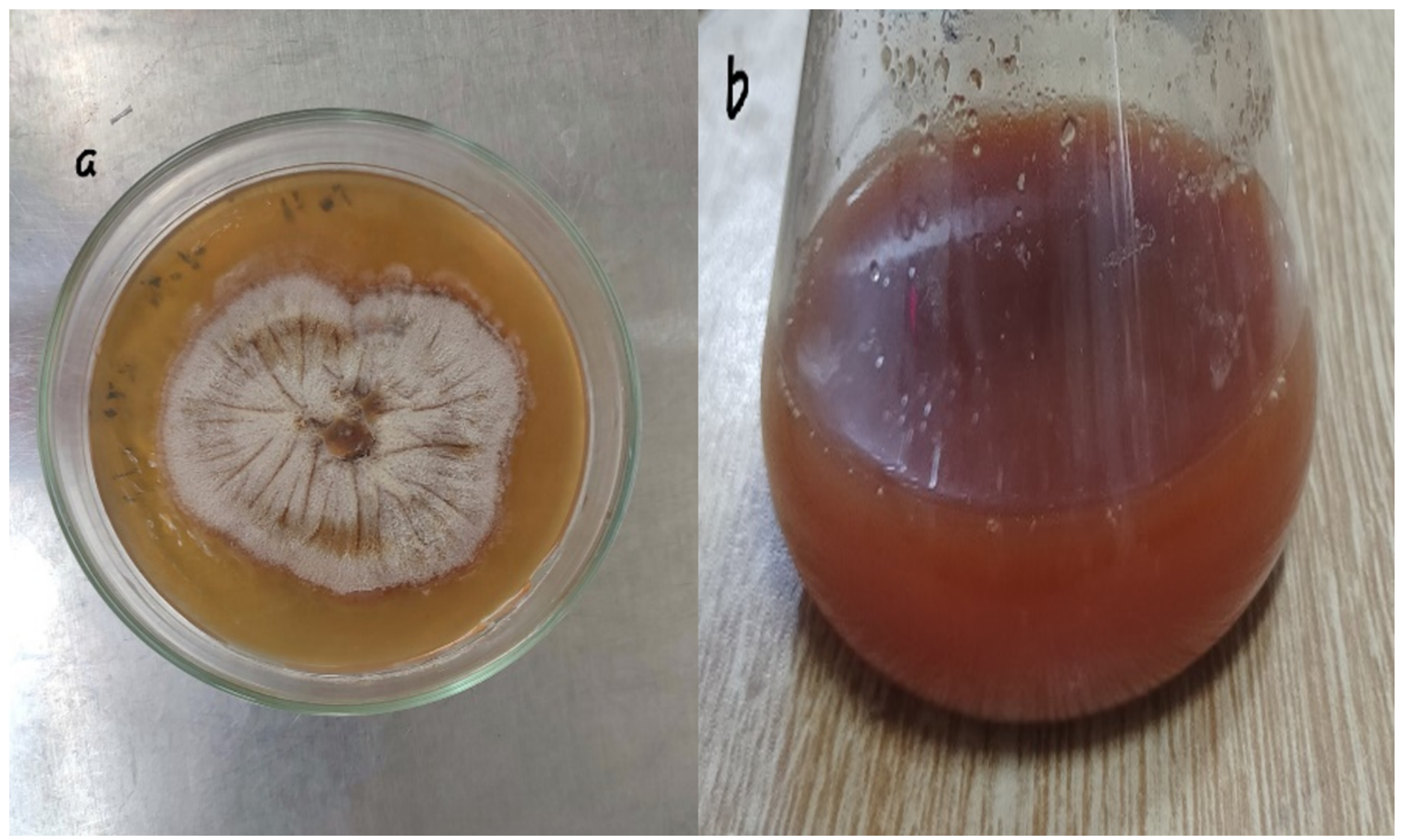

\section{Figure 1}

(a) Colony morphology on Sabouraud dextrose agar at $30^{\circ} \mathrm{C}$ for $7-9$ days (b) Growth in SDB sowing production of brown extracellular pigment

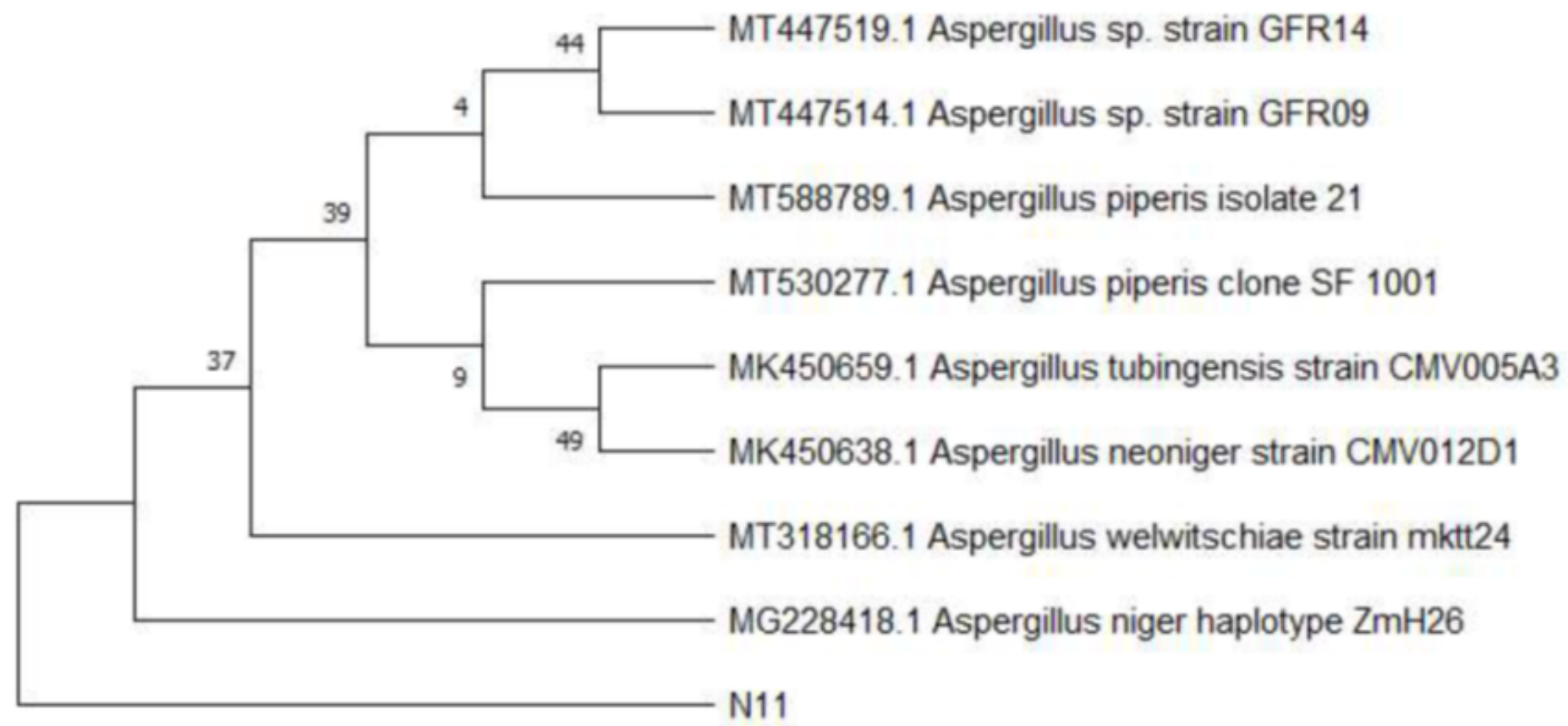

Figure 2 

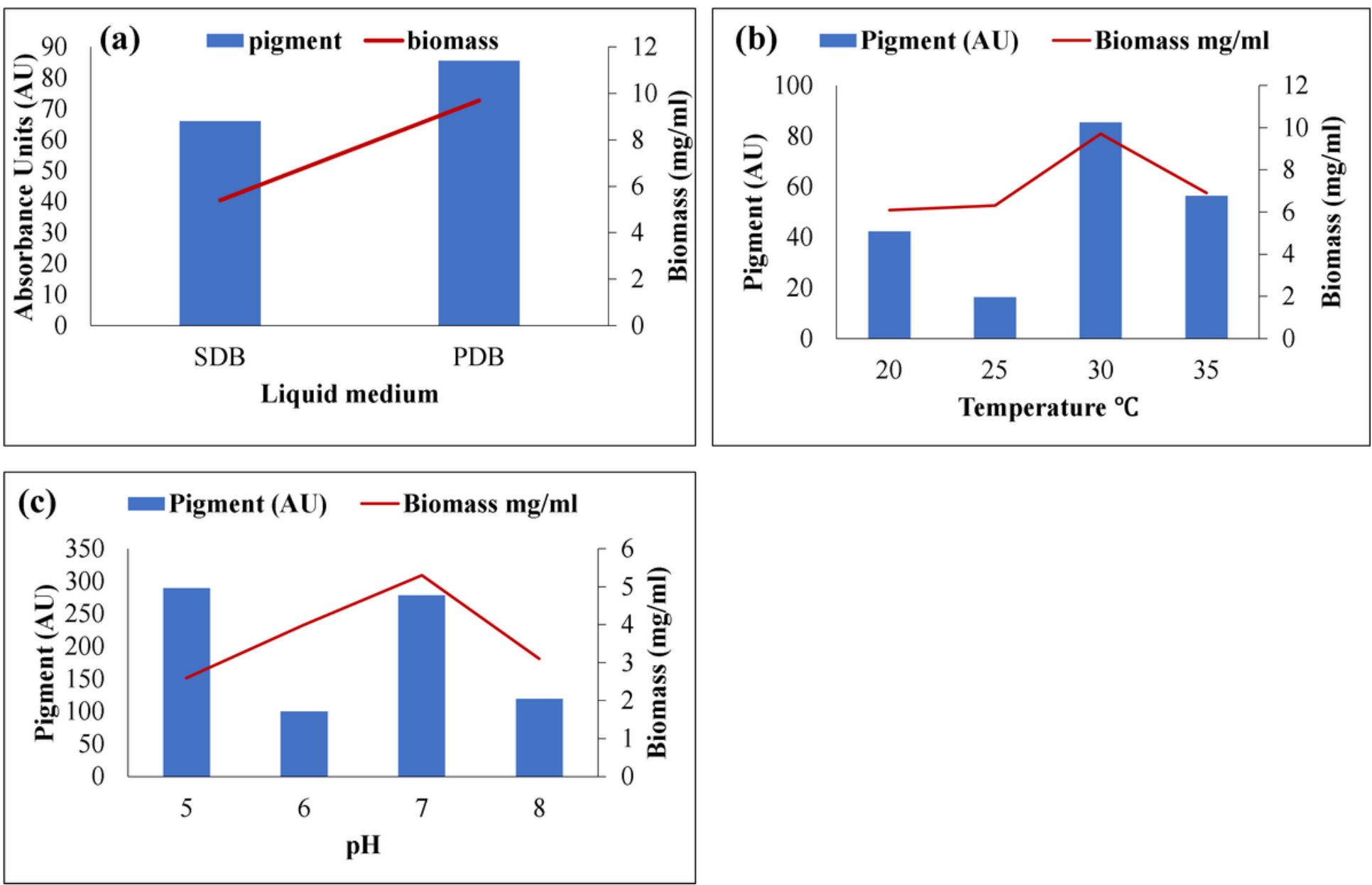

Figure 3

a Effect of different liquid mediums on pigment and fungal biomass production by Aspergillus sp. N11, b Effect of temperature on pigment and biomass production by Aspergillus sp. N11, c Effect of pH on pigment and biomass production by Aspergillus sp. N11. 

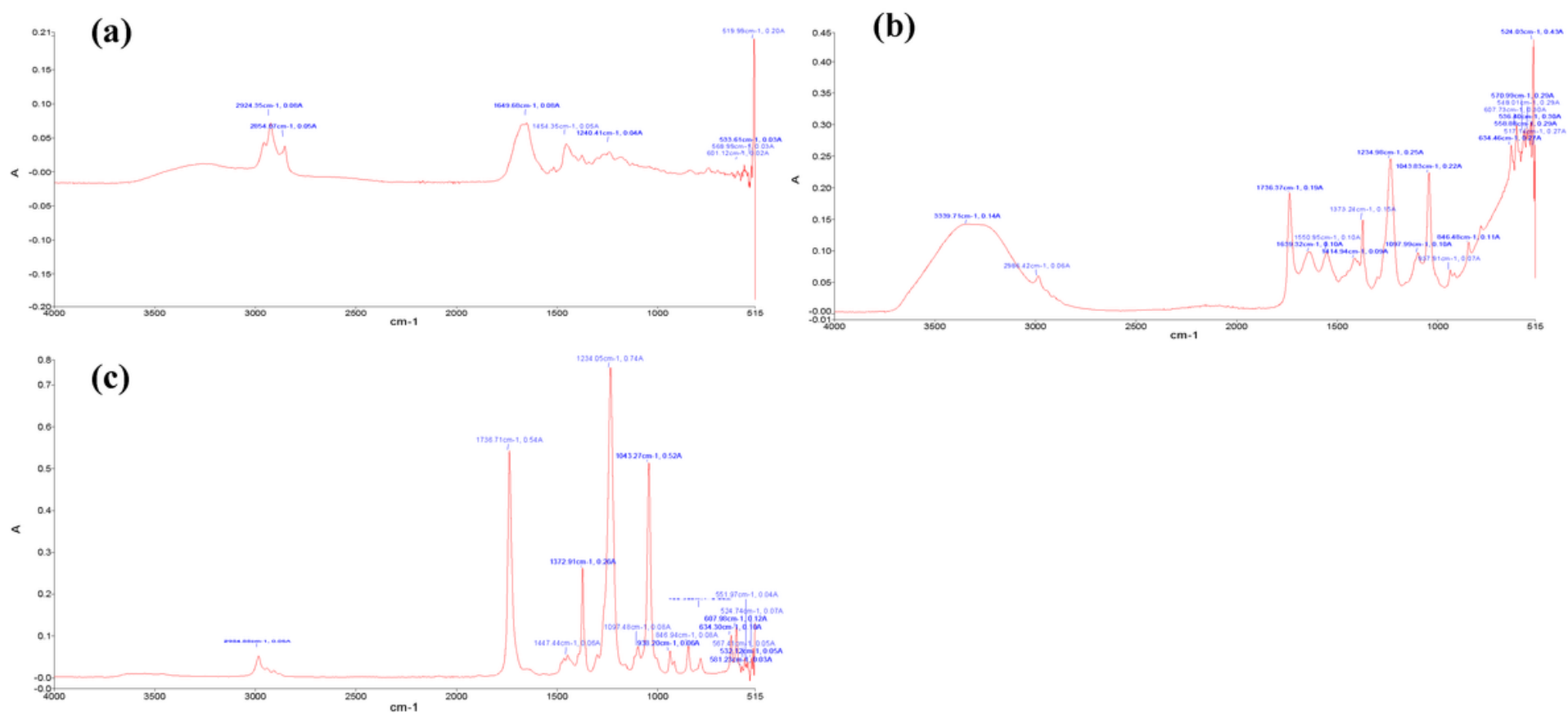

Figure 4

a FTIR analysis of Fraction 10 (yellow) of Aspergillus sp. N11, b FTIR analysis of Fraction 21 (brown) of Aspergillus sp. N11, c FTIR analysis of Fraction 34 (brown) of Aspergillus sp. N11. 


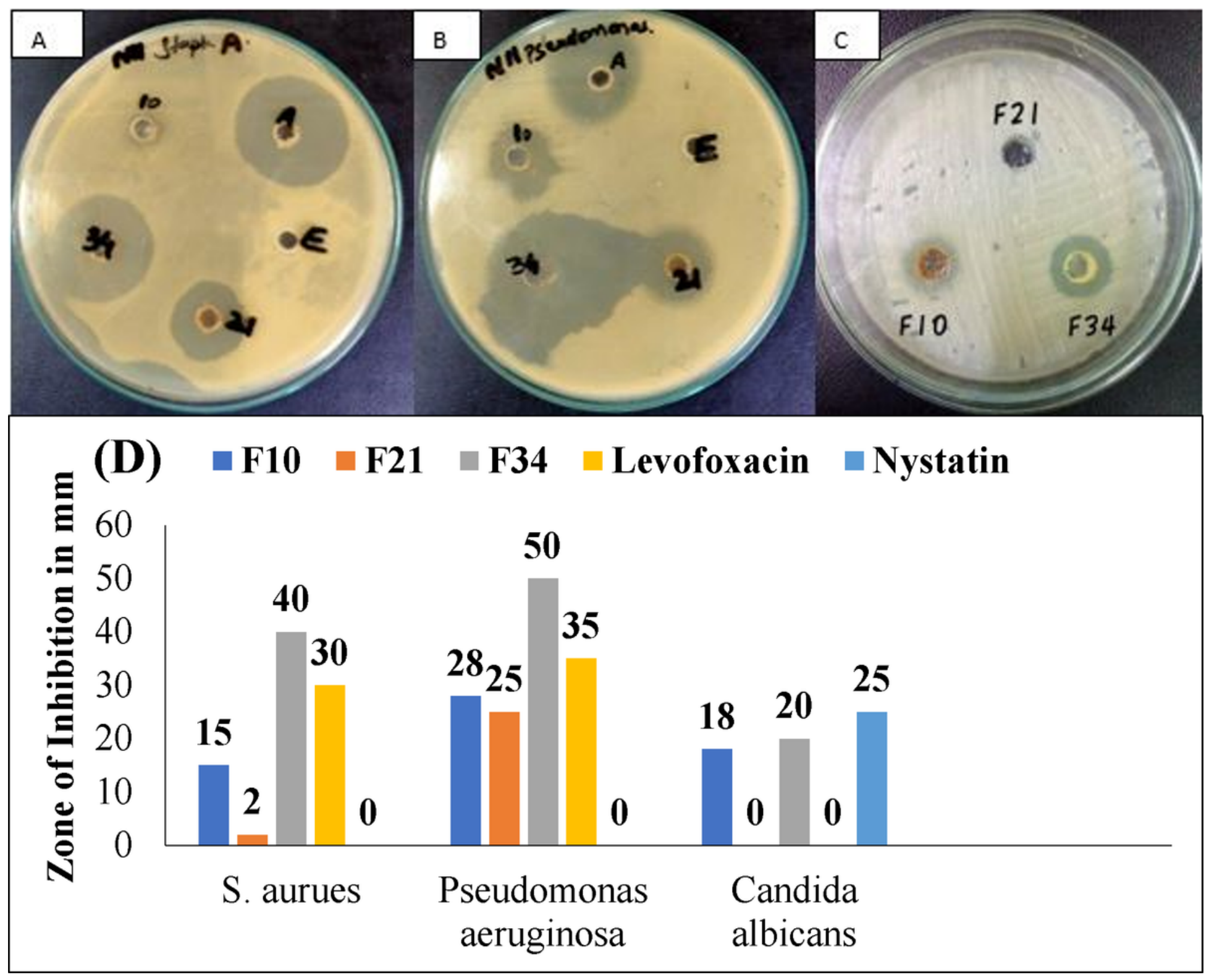

Figure 5

Antibacterial and Antifungal activity of purified pigments. Agar well diffusion method was used to evaluate the antimicrobial activity of F10, F21 and F34 against $S$. aureus (A), P. aeruginosa (B), C. albicans (C) and graphical representation of all results (D). 


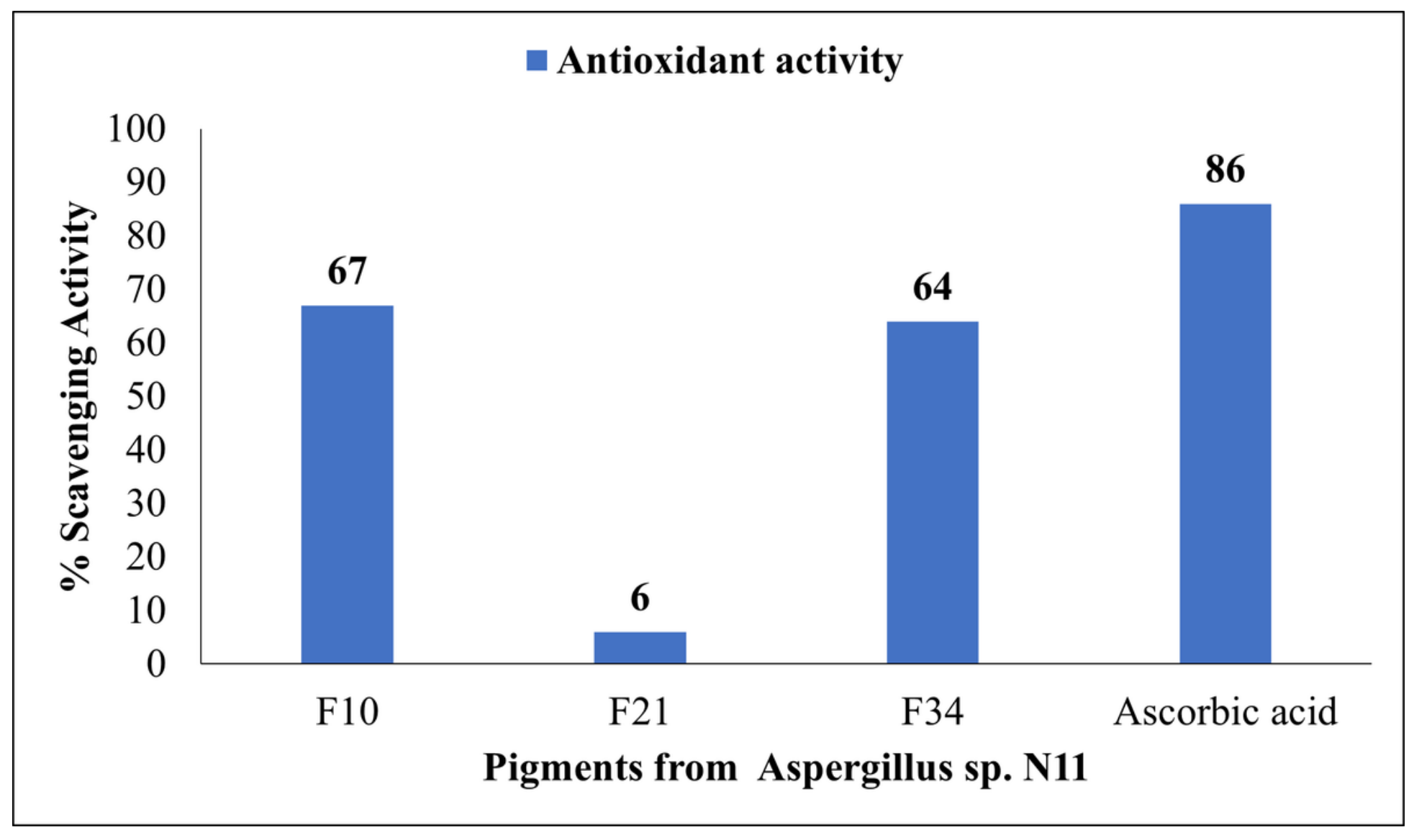

Figure 6

Antioxidant activity of purified pigments estimated by using DPPH assay

\section{Supplementary Files}

This is a list of supplementary files associated with this preprint. Click to download.

- Authorchecklist.docx 